\title{
Valorización de purines mediante pirólisis
}

\author{
Nadia Ruiz, Fernando Molinés, José Antonio Mateo, Isabel Fonts, Gloria Gea \\ Afiliación: Grupo de Procesos Termoquímicos (GPT) \\ Instituto de Investigación en Ingeniería de Aragón (I3A) \\ Universidad de Zaragoza, Mariano Esquillor s/n, 50018, Zaragoza, Spain. \\ Tel. +34-976762224, e-mail: nadiarui@unizar.es
}

\section{Resumen}

En este trabajo se propone el proceso de pirólisis como una posible vía de tratamiento de purines, que permite obtener energía renovable y un sólido, denominado biochar, con propiedades como enmienda orgánica. Se estudia el efecto de la temperatura de pirólisis sobre las propiedades del biochar.

\section{Introducción}

La producción anual de purines en España oscila entre $\operatorname{los} 40$ y 50 millones de toneladas. E1 desarrollo económico ha supuesto un crecimiento del sector ganadero, caracterizado por un modelo de ganadería intensiva cuyas explotaciones se han ido concentrando en zonas determinadas. Esta concentración ha supuesto la ruptura en el equilibrio que existía entre agricultura y ganadería. La gestión del purín mediante su aplicación agrícola no es apropiada en estas zonas donde la producción del residuo es muy elevada para el terreno disponible. En estas zonas, es necesaria la implementación de plantas de tratamiento, ya que una excesiva aplicación de purín al suelo origina importantes problemas de contaminación de aguas superficiales y subterráneas por nitratos, acumulación de fósforo, eutrofización, contaminación del suelo por acumulación de metales pesados, contaminación atmosférica por emisiones de amoníaco y gases de efecto invernadero, además de la generación de malos olores que origina un importante rechazo social. Por otro lado, debido al elevado contenido en agua de este residuo (95\% en masa), su transporte hacia zonas deficitarias para su uso agrícola supone un elevado coste económico e impacto ambiental, lo que también hace inviable esta opción. Una posible vía de tratamiento que permite la valorización energética del residuo es la digestión anaerobia mediante la obtención de biogás. Sin embargo, la actual reforma del sector eléctrico, junto al coste que suponen las tecnologías de limpieza del biogás y de la gestión del digestato ha provocado que este tratamiento no sea sostenible económicamente en el sector ganadero. Actualmente, una parte importante de los purines generados en zonas de ganadería intensiva se están aplicando incorrectamente al suelo.

La pirólisis del purín permite, además de recuperar los nutrientes del residuo, obtener energía renovable y productos de valor. Se generan tres productos, un gas y un líquido combustibles, y un sólido, biochar, con propiedades como enmienda orgánica [1]. Las principales ventajas medioambientales y agronómicas del uso del biochar son la eliminación de malos olores, la minimización de emisiones de amoníaco y de gases de efecto invernadero, la reducción en la lixiviación de nutrientes, la mejora de las propiedades fisicoquímicas y biológicas del suelo, así como la posibilidad de ser utilizado como fertilizante de liberación lenta [2].

El objetivo concreto de este trabajo es estudiar el efecto de la temperatura de pirólisis sobre el rendimiento y las propiedades del biochar de purines como enmienda orgánica, así como sobre las necesidades energéticas del proceso.

\section{Materiales y métodos}

Como materia prima se ha utilizado purín de vaca y gallinaza codigerido con restos agroalimentarios sometido a un tratamiento de secado térmico.

La pirólisis se ha llevado a cabo en un reactor de lecho fijo discontinuo para el sólido a una velocidad de calentamiento de $8^{\circ} \mathrm{C} / \mathrm{min}$ y a tres temperaturas finales de pirólisis $(350,450$ y 550 $\left.{ }^{\circ} \mathrm{C}\right)$. Durante el experimento se analiza en continuo la composición del gas lo que permite determinar su poder calorífico. Una vez finalizado el experimento se recogen por separado el líquido y el biochar.

Las propiedades analizadas en el biochar han sido, además del poder calorífico, las recomendadas por el protocolo IBI (International Biochar Initiative). Concretamente, $\mathrm{pH}$, conductividad eléctrica, superficie específica, distribución de tamaño de partícula, análisis elemental, humedad, volátiles, 
contenido en cenizas y metales. Con fines comparativos, estas propiedades también se han determinado en el purín utilizado como materia prima. Por otro lado, a partir del poder calorífico y los análisis elementales de la materia prima y de los productos de la pirólisis, se ha calculado las necesidades energéticas del proceso asumiendo que es posible recuperar todo el calor sensible y latente contenido en los productos de pirólisis.

\section{Resultados}

El producto mayoritario de la pirólisis de purines es el biochar, obteniéndose un rendimiento en torno al $50 \%$ en peso. El producto minoritario es el gas ( $15 \%$ en peso). Un aumento en la temperatura de pirólisis aumenta el rendimiento a gas, disminuyendo el rendimiento a biochar. Sin embargo, en el intervalo de estudio, dicho efecto no es notable.

La composición del gas obtenido varía con la temperatura. Se genera un gas con mayor porcentaje en $\mathrm{H}_{2}$, y por lo tanto, con mayor poder calorífico a medida que aumenta la temperatura. El poder calorífico del gas obtenido varía desde 6.5 $\mathrm{MJ} / \mathrm{m}^{3}$ (NTP) a $350{ }^{\circ} \mathrm{C}$ hasta $12 \mathrm{MJ} / \mathrm{m}^{3}$ (NTP) a $550{ }^{\circ} \mathrm{C}$, por lo que puede utilizarse como parte del combustible requerido en la etapa de secado térmico del purín. El líquido obtenido presenta dos fases, una fase acuosa, que es la mayoritaria, y una fase orgánica. El poder calorífico de la fase orgánica es $30 \mathrm{MJ} / \mathrm{kg}$, por lo que podría aprovecharse para aportar energía al proceso de pirólisis. Sin embargo, su contenido en nitrógeno ( $4 \%$ en peso) obligaría a un sistema de limpieza de gases de la combustión.

La Tabla 1 muestra algunas de las propiedades analizadas en el biochar y en el purín. El biochar obtenido es más básico que el purín, y podría ser aplicado a suelos ácidos como enmienda básica. Por otro lado, el biochar presenta valores de conductividad eléctrica menores que el purín, lo que es favorable para determinados cultivos, ya que suelos con elevadas conductividades impiden el desarrollo de plantas. Otra ventaja del biochar es que ocupa menos espacio que el purín, lo que facilita su almacenamiento y transporte. Además, dado que la humedad del biochar es muy inferior se evita el crecimiento de microorganismos. La aplicación del biochar también evita la emisión de malos olores y de gases de efecto invernadero puesto que su contenido en volátiles es mucho menor. El aumento de la relación N/C, y del contenido en fósforo que se duplica en el biochar, indica enriquecimiento en nutrientes, pero su liberación es más lenta. Aunque durante el proceso de pirólisis los metales se concentran en el biochar, a las temperaturas estudiadas, no se superan los límites establecidos por el IBI.

En el intervalo de estudio, la temperatura no afecta de forma notable en las propiedades del biochar, sin embargo, desde un punto de vista energético, es recomendable trabajar a temperaturas intermedias $\left(400-500^{\circ} \mathrm{C}\right)$.

\section{Conclusiones}

Las propiedades analizadas en el biochar de purines muestran que su uso como enmienda orgánica presenta ventajas medioambientales y agronómicas comparándolo con el uso directo del purín como fertilizante. La temperatura de pirólisis, en el intervalo estudiado, apenas afecta a las propiedades del biochar ni a los rendimientos de los productos del proceso de pirólisis. Sin embargo, temperaturas en el intervalo de 400-500 ${ }^{\circ} \mathrm{C}$ son recomendables desde un punto de vista energético.

\section{REFERENCIAS}

[1]. CAO, X., and HARRIS, W. Properties of dairy-manurederived biochar pertinent to its potential use in remediation. Bioresource Technology. 2010, 101(14), 5222-5228. Available from: doi: 10.1016/j.biortech.2010.02.052.

[2]. LEHMANN, J., DA SILVA, J.P., STEINER, C., NEHLS, T., ZECH, W., and GLASER, B. Nutrient availability and leaching in an archaeological Anthrosol and Ferrasol of the Central Amazon basin. Plant and Soil. 2003, 249(2), 343-357. Available from: doi:10.1023/a.1022833116184.

Tabla 1. Propiedades del purín y del biochar.

\begin{tabular}{|c|c|c|c|c|}
\hline & Purín & B.350 & B.450 & B.550 \\
\hline $\mathrm{pH}$ & 8 & 10 & 11 & 11 \\
\hline $\mathrm{CE}(\mu \mathrm{S} / \mathrm{cm})$ & 2193 & 1405 & 1400 & 1421 \\
\hline Humedad (\%) & 13.3 & 1 & 0.8 & 0.5 \\
\hline Volátiles (\%) & 66 & 29 & 24 & 19 \\
\hline N/C & 0.03 & 0.06 & 0.05 & 0.05 \\
\hline
\end{tabular}

